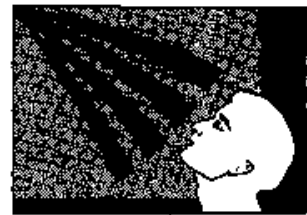

FORMAGAO DOPSICÓLOAO

Está em andamento uma proposta de mudança curricular cuja principal caracteristica é transformar o curriculo num objeto de pesquisa, envolvendo a comunidade docente e discente num trabalho conjunto. As diversas etapas de conduçāo desta proposta e seu desenrolar säo apresentados aqui pelo professor José Gonçalves Medejros, coordenador do Curso de Psicologia da Universidade Federal de Santa Catarina.

radicionalmente, chefe de Departamento e coordenador de Curso trabalham independentemente. $O$ chefe do Departamento cuida das questōes profissionais dos professores e o coordenador cuida das questỗes acadêmicas e das relações com os alunos. $\mathrm{Na}$ UFSC (SC), propusemos a formação de uma equipe de trabalho, acompanhada de uma proposta, de tal modo que chefe, coordenador de Curso e demais coordenadores (de pesquisa, de extensão, etc.) pudessem trabalhar coordenadamente a partir de uma proposta única de trabalho. Também propusemos a eleição dos membros da chapa em Assembléia Geral do Curso, de forma direta, com voto aberto, universal (tradicionalmente o voto é secreto). A comunidade acatou; apresentamo-nos, entāo, com uma chapa e um programa (não houve chapa concorrente) e fomos referendados pelo voto da maioria.

Uma das propostas de nossa equipe era trabalhar com o currículo que não mais satisfazia as expectativas de professores e alunos. Desde 1977, tem ocorrido, nos cursos de Psicologia, reformas curriculares, com mudanças em aspectos como: exclusāo ou inclusāo de disciplinas, alteração de nome de disciplinas, inclusão ou exclusão de pré-requisitos, remanejamento de disciplinas de uma fase para outra, etc. Em nosso levantamento, conseguimos identificar dez categorias relacionadas a alteraçōes curricu. lares. No curso de Psicologia da 24 PSICOLOGIA, CIÉNCIA E PROFISSĀO

\section{0 currículo como objeto de pesquisa}

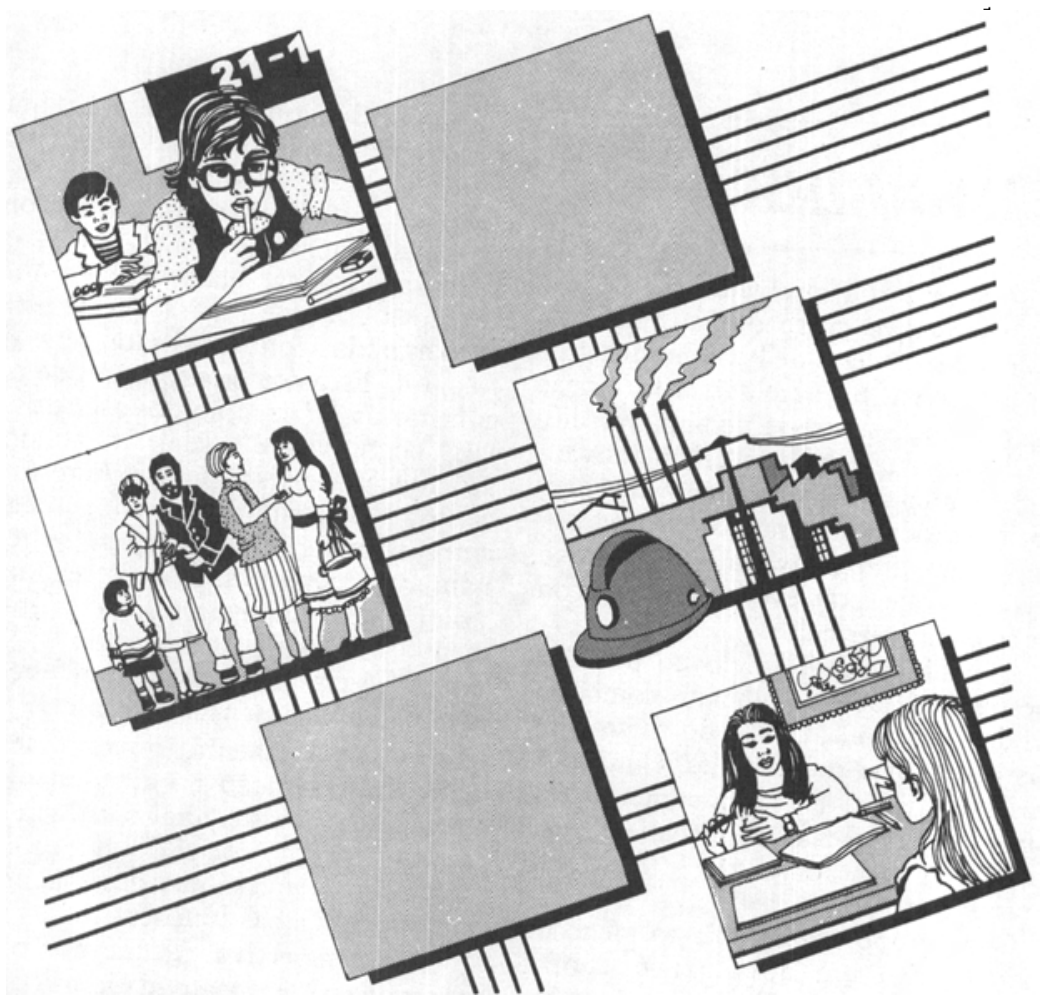

UFSC, desde sua criação até hoje (foi criado em 1977), arrolamos 108 alterações dessa natureza. Se, de fato, reformar currículo dessa maneira fosse eficiente, teriamos o melhor currículo do Brasil e não é o que ocorre. Essas alteraçōes curriculares näo mexem com a natureza do conhecimento que está sendo produzido (quando está) e nem mexe na relação ensinopesquisa-extensão. Ocorrem reformas curriculares, mas a estrutura permanece a mesma. Diante disso, fizemos a proposta de modificar o currículo. Tenho enfatizado modificar e Dāo reformar, pois entendo que na reforma ocorrem retoques com a manutenção da estrutura, impedindo avanços de qualidade.

Tradicionalmente, as decisöes so. bre modificaçōes de currículo são tomadas nos Colegiados dos Cursos. Para evitar isso, propusemos uma mudança (informal) na composição do Colegiado. Legalmente, temos direito a 10 professores e 1 aluno, mas houve uma combinação interna para torná-lo paritário. Participam e vo- tam 10 professores $e 10$ alunos e apenas 11 assinam (ou seja, os 10 professores e o representante oficial dos alunos). Chamamos a esta nova forma de organização de CURRICULINTE. Já que não tivemos uma Assembléia Nacional Constituinte livre e soberana, nem tivemos possibilidade de eleger uma Estatuinte Universitária (negada pelo Conselho Universitário), pelo menos, no curso de Psicologia, criamos a Curriculinte, livre e soberana. Estamos vivendo esse processo há aproximadamente um ano.

Para garantir a participação de toda a comunidade do Curso, procuramos trabalhar de forma que abrangesse o maior número possível de interessados. De que forma conseguiríamos este objetivo? Dividimos o processo em quatro etapas. Estamos, no momento, realizando a primeira que consiste no acúmulo de discussões gerais e de geração de subsídios para as etapas posteriores. Estes subsídios estão sendo buscados através dos 13 projetos de pesquisa, ora em andamento. 
Gostaríamos de realçar a participação, sobretudo de alunos, nas assembléias que deliberam sobre o processo e nos projetos de pesquisa. Foram montados 13 projetos e conseguimos um envolvimento muito grande. Hoje contamos com aproximadamente $\mathbf{4 0}$ alunos de graduação trabalhando efetivamente nos projetos, com supervisão direta de 5 professores. Para os alunos é considerada uma atividade extra-curricular (não recebem créditos por este trabalho) e alguns projecos säo financiados por bolsas de iniciação à pesquisa da Universidade ou através do FUNPESQUISA. Resultados parciais desses projetos foram, em 1988, apresentados na XVIII Reuniāo Anual de Psicologia de Ribeirão Preto. É nosso objetivo envolver cada vez mais a participação de alunos no processo de modificação curricular, de tal modo que, quando tivermos mudado o currículo, já tenhamos engajado uma grande parcela deles. São, ao todo, 260 alunos regularmente matriculados e quase $20 \%$ estāo engajados no processo de produção de conhecimento sobre currículo.

Mais ainda, a participação dos alunos tem importância fundamental em termos pedagógicos, uma vez que procuramos associar diretamente o trabalho de pesquisa ao trabalho acadêmico. $O$ currículo passa a ser objeto de pesquisa. Entendemos que o processo de modificação curricular deva se tornar um legítimo objeto de pesquisa, como qualquer outro que fazemos no Departamento. Os 13 projetos de pesquisa em andamento são: 1. Caracterização do corpo discente (que tipo de aluno entra para o curso, qual é a sua formaçāo, as suas expectativas, de onde vem etc.); 2 . Avaliação da relação entre as áreas de conhecimento biologia/piscologia (em alguns cursos existe uma quantidade exagerada de disciplinas biológicas, o que acaba gerando insatisfação entre os alunos); 3. Levantamento histórico do Curso e do Departamento de Psicologia. (Como o curso se desenvolveu desde sua criação? Quais sảo os grupos e que tipo de orientação de trabalho assumem); 4. Psicologia, Ciência e Profissão: o ponto de vista dos profissionais; 5 . 0 pisicólogo de Santa Catarina: quem é, o que faz e como avalia sua formação (estes dois projetos - 4 e 5 - procuram verificar como estão trabalhando os psicólogos formados no nosso curso e nos cursos do País. $O$ currículo atual está ajudando ou dificultando o trabalho de inserção na sociedade?); 6. Currículos comparados de Psicologia: Brasil versus América Latina (tentativa de detectar se existe predominância de uma ou outra área ou orientação técnico-científica no Brasil e em alguns países latino-americanos); 7. A atuação do psicólogo na rede pública do II grau (sabemos que existe hoje uma grande demanda em termos de professores para dar aula de Psicologia no II grau. A partir deste projeto, pretendemos reestruturar a parte de licenciatura do Curso de graduação); 8. Análise do atual currículo de Psicologia da UFSC: como ele é concretizado; 9. Uma análise do panorama das pesquisas em Psicologia no País (este projeto começou recentemente e é fundamental sabermos que rumo toma a pesquisa, que tipo de conhecimento está sendo produzido, a quem ele está servindo etc.); 10 . O que fazem os psicológos que não se enquadram nas áreas tradicionais (clínica, organizacional, escolar)? ; 11. A contribuição do psicólogo em equipe interdisciplinar; 12 . Um procedimento para identificar alternativas socialmente relevantes de atuação do psicólogo junto à populaçāo; 13. Formação e atuação do psicólogo: levantamento bibliográfico.

Após a realização destes projetos de pesquisa e recorrendo a outros dados a respeito da profissão no País, entraremos na segunda etapa do processo de mudança curricular. A Curriculinte vai avaliar os dados produzidos pelas pesquisas e divulgá-los junto à comunidade. Depois de discutilos, tiraremos as diretrizes gerais e objetivos do currículo e os levaremos para a Assembléia Geral, que se constitui na instância final do processo de decisão.

Ao mesmo tempo que se discute a nossa proposta de modificaģăo curricular, rediscute-se na Universidade um projeto de reforma academica. Uma das propostas, com grande probabilidades de ser aceita, é a autonomia dos Centros e dos Colegiados de Cursos. Uma das propostas e que o processo de modificaçāo curricular se encerre nos Colegiados dos Cursos. Se de fato isto vier a ocorrer, teremos possibilidades de formular e de gerir o nosso próprio curriculo, independente das instâncias superiores.

$\mathrm{Na}$ etapa 3, surgirz̃o os encaminhamentos para questóes como: como vão ser os conteúdos dos currículos e como vāo estar integrados com os conteúdos de pesquisa e extensão? $Q u a l$ vai ser a dinâmica do curso? $O$ trabalho vai ocorrer somente em sala de aula ou fora dela? Em que proporçāo?

Na etapa 4 haverá a deliberação sobre propostas de currículo. A idéa inicial é terminar essas etapas até o próximo ano porque existe uma data limite na Universidade para que scjam feitas todas as propostas de alteraçōes curriculares a serem implantadas no ano seguinte. Particularmente, não acredito que seja possivel terminá-lo. Este trabalho deve ocorrer normalmente e sem atropelos. Por que não demorar mais tempo e torná-la uma proposta que possa servir de modelo para outros cursos de Psicologia do País?

Uma dificuldade que temos entrentado, antes mesmo de começar a implantar mudanças, $\varepsilon$ a pouca participaçāo dos professores. Uma estratégia é envolvê-los cada vez mais nos trabalhos de pesquisa, o que não está sendo fácil conseguir. Outra questzóo delicada que näo abordamos ainda é a avaliaçăo do corpo docente.

Para finalizar, um recado: existe hoje um movimento denominado Articulação Nacional pela Melhoria da Qualidade do Ensino da Psicologia, em fase de articulaçăo com os cursos de psicologia do País. Esperamos que esta articulação possa tambern se tornar uma forma de pressāo nos Departamentos, para envolver os professores nos projetos de melhoria do ensino. Temos, hoje, professores que nunca pensaram em fazer pesquisa e que jâ nos têm procurado. Estamos apostando que professores e alunos văo envolver-se cada vez mais e que isso possa modificar as estruturas departamentais em direçāo a um ensino competente, político e voltado para o interesse da maioria da população brasileira.

PSICOLOGIA, CIÉNCIA E PAOFISSÃO 25 